\title{
THE ROLE OF THE MAVERICK FIRM CONCEPT IN EUROPEAN COMMISSION MERGER DECISIONS
}

\author{
Joseph Bromfield* and Matthew Olczak ${ }^{\dagger}$
}

22nd May 2018

\begin{abstract}
The maverick firm concept recognises the fact that certain firms may be inherently different from their rivals. This paper provides evidence on the use of this concept in European Commission merger decisions. We find that it has been relatively rarely used. However, where it has, maverick behaviour has been considered in a diverse range of industries and the candidate firms have been both insiders and outsiders to the merger. We then examine in detail the few cases where the existence of a maverick was eventually established by the Commission. All of these cases occurred after the 2004 change in the Merger Regulation and predominantly when analysing the likelihood that unilateral effects would result from the merger. We suggest that this may be reconciled with economic theory by a more general need to take into account post-merger product repositioning.
\end{abstract}

JEL classification: L41, K21

Key words: mavericks, mergers, collusion, unilateral effects

*Birmingham Business School, University of Birmingham, Birmingham, B15 2TT, email: j.p.bromfield@bham.ac.uk

${ }^{\dagger}$ Aston Business School, Aston University, Birmingham, B4 7ET, UK, email: m.olczak@aston.ac.uk 


\section{INTRODUCTION}

Economic theory and legal analysis have long recognised the possibility that certain firms may be inherently different to their rivals and that this has implications for merger policy. To date, the most comprehensive legal discussion of these so called maverick firms comes from Baker ${ }^{1}$ who defines these as firms that constrain market coordination. In the first paper to theoretically consider maverick firms, $\mathrm{Kwoka}^{2}$ models these as firms that exhibit especially rivalrous behaviour. He then shows that merging with a maverick firm can be profitable if as a result the maverick is eliminated from the market and coordination is facilitated. Therefore, from early on the maverick concept was firmly grounded in coordinated effects (or tacit collusion) merger analysis. ${ }^{3}$

The concept has also become established in merger guidelines published by competition agencies in the US and Europe. The US guidelines suggest that a maverick firm may have greater excess capacity than its rivals or the propensity to expand its sales in secret. ${ }^{4}$ Alternatively, previous literature suggests that maverick behaviour may arise due to cost differences ${ }^{5}$, innovation ${ }^{6}$ or simply due to managerial preference ${ }^{7}$. In addition, attempts to develop empirical techniques for maverick identification based on firm behaviour have also been developed. ${ }^{8}$

Merger guidelines and the previous literature suggest that there are a number of avenues through which maverick firms may influence merger analysis. First, consistent with the Kwoka ${ }^{9}$ model described above, the US guidelines ${ }^{10}$ recognise that:

\footnotetext{
${ }^{1}$ Baker, J.B., 2002, Mavericks, Mergers, and Exclusion: Proving Coordinated Competitive Effects Under the Antitrust Laws, New York University Law Review: 135-203.

${ }^{2}$ Kwoka, Jr. J.E., 1989, The Private Profitability of Horizontal Mergers with Non-Cournot and Maverick Behaviour, International Journal of Industrial Organization, 7: 403-11.

${ }^{3}$ For an overview of coordinated effects analysis in merger policy see for example Ivaldi, M., Jullien, B., Rey, P., Seabright, P., and Tirole, J., 2003, The Economics of Tacit Collusion, Final Report for DG Competition, European Commission.

${ }^{4}$ Department of Justice and Federal Trade Commission, Horizontal Merger Guidelines, April 1992, revised April 1997, p.21-22.

${ }^{5}$ Ivaldi et al., The Economics of Tacit Collusion, supra note 3.

${ }^{6}$ Owings, T. M., 2013, Identifying a Maverick: When Antitrust Law Should Protect a Low-Cost Competitor, Vanderbilt Law Review, 66: 323-354.

${ }^{7}$ Langenfeld, J. A., 1996, The Merger Guidelines as Applied, The Economics of the Antitrust Process, 41-64, Springer US.

${ }^{8}$ See for example Breunig, R. and Menezes, F., 2008, Empirical Approaches for Identifying Maverick Firms: An Application to Mortgage Providers in Australia, Journal of Competition Law and Economics, 4(3): 811-836.

${ }^{9}$ Kwoka, The Private Profitability of Horizontal Mergers with Non-Cournot and Maverick Behaviour, supra note 2.

${ }^{10}$ Department of Justice and Federal Trade Commission, Horizontal Merger Guidelines, supra note 4, p. 21 .
} 
"In some circumstances, coordinated interaction can be effectively prevented or limited by maverick firms - firms that have a greater economic incentive to deviate from the terms of coordination than do most of their rivals (e.g., firms that are unusually disruptive and competitive influences in the market). Consequently, acquisition of a maverick firm is one way in which a merger may make coordinated interaction more likely, more successful, or more complete."

In a similar fashion, the European Commission (EC) merger guidelines ${ }^{11}$ state that:

"[a] merger may involve a 'maverick' firm that has a history of preventing or disrupting coordination, for example by failing to follow price increases by its competitors, or has characteristics that gives it an incentive to favour different strategic choices than its coordinating competitors would prefer."

In both cases the concern is that coordination is facilitated post-merger as the constraint previously imposed by the maverick is removed. However, second, the US guidelines ${ }^{12}$ also recognise that the existence of a maverick amongst the merging parties can reduce coordination concerns:

"marginal cost reductions may make coordination less likely or effective by enhancing the incentive of a maverick to lower price or by creating a new maverick firm."

Both of these avenues focus on situations where the maverick is an insider i.e. one of the merging parties. In contrast, Baker ${ }^{13}$ makes an important distinction between whether the maverick is involved in or an outsider to the merger. He

\footnotetext{
${ }^{11}$ European Commission, 2004, Guidelines on the Assessment of Horizontal Mergers under the Council Regulation on the Control of Concentrations Between Undertakings, para. 42.

${ }^{12}$ Department of Justice and Federal Trade Commission, Horizontal Merger Guidelines, supra note 4, p.30.

${ }^{13}$ Baker, Mavericks, Mergers, and Exclusion: Proving Coordinated Competitive Effects Under the Antitrust Laws, supra note 1.
} 
describes how a maverick that is an outsider may continue to constrain coordination and thus prevent the merger from harming competition.

Despite the maverick firm concept now being firmly established in guidelines, there is relatively little evidence on its use in merger cases. One exception is Kolasky ${ }^{14}$ who suggests that the concept has become increasingly important in coordinated effects analysis in the US, citing a number of cases where it has played a key role. Another is Coate ${ }^{15}$ who studies US horizontal merger cases between 1993 and 2003. He finds that whilst relatively rare, if the Federal Trade Commission supports a coordinated effects case by arguing that a maverick will no longer be able to have a constraining effect on the market, the merger is more likely to be challenged.

The aim of this paper is to conduct a detailed analysis of the use of the maverick firm concept in European Commission (EC) merger decisions. We will provide evidence of how frequently the concept is used. Then, for those cases where it did play a key role, we then analyse how it was applied and how it influenced the decision. In order to establish the frequency with which the EC has used the concept, we conducted a detailed search of all EC merger decisions between 2000 and 2013 in which there were competitive concerns. This covers the period where the concept has been used in Europe, as Lyons ${ }^{16}$ confirms that the term was not used in a single European case in the 1990s.

As reported in detail in Section II, we find that during the period studied, whilst rare, the maverick firm concept has been applied in 22 merger cases. However, across these case, maverick behaviour has been considered in a diverse range of industries and the potential maverick may be either an insider or outsider to the merger. Furthermore, even within these 22 cases the EC did not always eventually establish the existence of a maverick. Therefore, in Section III, we examine in detail the few cases in which the EC did establish the presence of a maverick. Here, the maverick is usually a small firm which is an insider to the merger and is perceived pre-merger to be an aggressive competitor. Section IV then discusses the fact that all of the cases in which the EC established the existence of a maverick occurred after an important change to the EC Merger Regulation (ECMR) that occurred to 2004. This change affected the theories of

\footnotetext{
${ }^{14}$ Kolasky, W. J., 2002, Coordinated Effects in Merger Review: From Dead Frenchmen to Beautiful Minds and Mavericks, US Department of Justice, Washington.

${ }^{15}$ Coate, M. B., 2006, Economic Models and the Merger Guidelines: A Case Study, Review of Law \& Economics, 2(1): 53-84.

${ }^{16}$ Lyons, B., 2008, Mavericks in Merger Analysis, Presentation at the Economic Developments in Competition Law, CRA Conference, Brussels, 3rd December.
} 
harm available to the EC. Therefore, we examine the theory of harm in relation to which the role of the maverick was considered. We find that, in contrast to the existing theory on mavericks and the merger guidelines, this was predominantly within the analysis of unilateral effects. We then discuss the extent to which this can be reconciled with economic theory. Finally, Section V concludes on the current role of the maverick concept in European merger policy.

\section{THE MAVERICK CONCEPT IN EC MERGER CASES}

\section{A Population of mergers examined}

Between January 2000 and December 2013 there were over 4000 merger cases decided by the EC. ${ }^{17}$ Of these, over $90 \%$ were cleared at the Phase 1 stage (Article $6.1 \mathrm{~b}$ ). Since these were quickly cleared with no competitive concerns it is highly unlikely that authorities would regard the maverick concept as relevant during their investigation. As a result these cases are omitted from our analysis. ${ }^{18}$ In addition, we omit the handful of cases for which no English report was available. The sample we are left with comprises of 274 cases. These are summarised in Table 1 by decision type.

Table 1: Total cases by decision type

\begin{tabular}{|c|c|}
\hline Decision Type & No. of cases \\
\hline \hline Phase I remedies (Art 6.1b compatible with commitments) & 163 \\
\hline Phase II clearance (Art 8.1 compatible) & 24 \\
\hline Phase II remedies (Art 8.2 compatible with commitments) & 75 \\
\hline Prohibition (Phase II) (Art 8.3) & 12 \\
\hline Total & $\mathbf{2 7 4}$ \\
\hline
\end{tabular}

\section{B Cases where the maverick concept was applied}

We are interested in whether the concept was applied in our sample of cases.

\footnotetext{
${ }^{17}$ See http://ec.europa.eu/competition/mergers/statistics.pdf for detailed statistics.

${ }^{18} \mathrm{We}$ conducted a search on a random sample of $5 \%$ of these cases and found that the maverick term only appeared in $1.5 \%$ of cases (3 out of 196). Furthermore, in these cases the term was used only fleetingly and the possible existence of a maverick was immediately dismissed.
} 
To investigate this, each case report was searched for reference to a maverick. This revealed that the concept was applied in only $22(8 \%)$ of the 274 merger cases.

\section{B.1 Sectors}

Next, we consider the industries in which the concept was applied. The table in the Appendix describes the sectors covered by our sample ${ }^{19}$ and the proportion of these in which the concept was applied. This shows that the sectors where the concept was frequently used were "Information and Communication", "Electricity, Gas, Steam and Air Conditioning" and "Wholesale and Retail Trade; Repair of Motor Vehicles and Motorcycles". With regard to Information and Communication, there were five maverick cases. Specifically, these related to the mobile telecommunications industry $(2 \text { cases })^{20}$, portable navigation devices ${ }^{21}$, databases ${ }^{22}$, and contact line engineering (for railway lines) ${ }^{23}$. In the Electricity and Gas category there were 3 maverick cases, all related to gas supply or gas products. ${ }^{24}$ Finally, there were 4 cases within the Wholesale and Retail Trade category which covered a broad range of markets with no clear common features. ${ }^{25}$ Overall, it is apparent that the concept has been applied to a diverse range of industries, including both retail products supplied to final customers and upstream wholesale markets.

\footnotetext{
${ }^{19}$ The table is constructed using the NACE sector codes with which the EC categories each case. Often, cases cover several divisions within a sector. In such instances, we record the sector only once. It is also not uncommon for cases to cover multiple sectors and in such cases each of these is recorded in the table.

${ }^{20}$ T-Mobile Austria/tele.ring, Commission decision of 26th April 2006, case number IV/M.3916 and T-Mobile/Orange, Commission decision of 1st March 2010, case number IV/M.5650.

${ }^{21}$ TomTom/Tele Atlas, Commission decision of 14th May 2008, case number IV/M.4854.

${ }^{22}$ Oracle/Sun Microsystems, Commission decision of 21st January 2010, case number IV $/$ M.5529.

${ }^{23}$ Siemens/VA Tech, Commission decision of 13th July 2005, case number IV/M.3653.

${ }^{24}$ DONG/Elsam/Energie E2, Commission decision of 14th March 2006, case number IV/M.3868; Linde/BOC, Commission decision of 6th June 2006, case number IV/M.4141 and RWE/Essent, Commission decision of 23rd June 2009, case number IV/M.5467. Moreover, in 2 other cases (M.2389 Shell/DEA, Commission decision of 20th December 2001, case number IV/M.2389 and M.2533 BP/E.ON, Commission decision of 20th December 2001, case number IV/M.2533.) the product in the market of concern was ethylene, a gas, although these cases were classified under manufacturing.

${ }^{25}$ The cases here cover wholesale of electrical products, household appliances and construction materials and sanitary equipment (Rexel/Hagemeyer, Commission decision of 22nd February 2008, case number IV/M.4963), wholesale of computer equipment (TomTom/Tele Atlas, supra note 21), retail of fuel (StatoilHydro/ConocoPhillips, Commission decision of 21st October 2008, case number IV/M.4919), and wholesale of sugar (Südzucker/ED\&F Man, Commission decision of 16th May 2012, case number IV/M.6286).
} 


\section{B.2 Decision type}

Table 2 describes the decisions in the cases in which the concept was applied.

Table 2: Application of the maverick concept by decision type

\begin{tabular}{|c|c|}
\hline Decision Type & No. of cases \\
\hline \hline Phase I remedies & 8 \\
\hline Phase II clearance & 4 \\
\hline Phase II remedies & 10 \\
\hline Prohibition & 0 \\
\hline Total & $\mathbf{2 2}$ \\
\hline
\end{tabular}

This shows that over one third are cases where remedies were imposed in Phase I. However, as a proportion of total decisions the concept was more likely to be applied in the more detailed Phase II enquiries ( $13 \%$ compared to $5 \%$ ). This is what we might expect since cases where there was a potential maverick are more likely to require detailed investigation. Additionally, from Table 2 we note that the concept has been applied more frequently in cases where remedies were imposed ${ }^{26}$ but not, to date, in cases where the merger was prohibited outright. However, as a proportion of total cases the concept was applied in more clearance decisions than intervention decisions (17\% compared to $7 \%$ ).

\section{Insider or outsider?}

As discussed in the introduction, the maverick firm concept is typically applied in a setting in which one of the merging parties is the maverick. Although this was the most common application, in our sample there were 9 cases (38\%) in which the firm considered to be a maverick was outside the merger. If the EC established that such a firm was a maverick, we would expect the likelihood that the merger is cleared to increase. Since so far we have examined cases where the existence of a maverick was merely considered, we will now identify in which of these this was eventually established.

\footnotetext{
${ }^{26}$ However, note that due to the typically multi-market nature of these mergers, the remedy was no necessarily imposed in the market where the concept was applied.
} 


\section{CASES WHERE THE EXISTENCE OF A MAVERICK WAS ESTABLISHED}

An in-depth reading of the 22 cases reveals that there were only 5 in which the EC established the existence of a maverick and then analysed the consequences of this further. ${ }^{27}$ These were T-Mobile Austria/tele.ring ${ }^{28}$, Linde/BOC ${ }^{29}$, StatoilHydro/ConocoPhillips ${ }^{30}$, Oracle/Sun Microsystems ${ }^{31}$ and T-Mobile/Orange ${ }^{32}$. In the other 17 cases, typically the EC either suggested that a particular firm could perhaps play such a role, but did not establish this ${ }^{33}$, or more broadly discussed the potential for mavericks in the industry ${ }^{34}$.

\section{A Nature and size of the maverick}

Focusing on the 5 cases where mavericks were established, we can make a number of observations about the nature and size of the maverick. First, the EC often portrays these firms as aggressive competitors. For example, in the case of Linde/BOC:

"The removal of Linde as an aggressive 'maverick' increases the risk of tacit collusion in this market and thereby raises serious doubts as to the compatibility of the merger with the common market." 35

In addition, the firms identified as maverick were typically small; in the case of Linde with a market share of less that $5 \%$. In general, the average market share

\footnotetext{
${ }^{27}$ We impose strict criteria for a case to be included here. To illustrate, take the Sony/BMG, Commission decision of 3rd October 2007, case number IV/M.3333. In response to third parties' claims that there would be collusion post-merger, the EC suggested that both EMI and Warner were '....significant 'mavericks' and would still have the power to jeopardy any attempt of collusion" (p.119). However, we do not include this case as the maverick role was not discussed further by the EC, with other arguments instead used to rule out coordinated effects.

${ }^{28}$ T-Mobile Austria/tele.ring, supra note 20.

${ }^{29}$ Linde/BOC, supra note 24 .

${ }^{30}$ StatoilHydro/ConocoPhillips, supra note 25.

${ }^{31}$ Oracle/Sun Microsystems, supra note 22.

${ }^{32} \mathrm{~T}$-Mobile/Orange, supra note 20.

${ }^{33}$ See for example Siemens/VA Tech, supra note 23, para 174, where the EC considers VA Tech as a possible maverick but that there is insufficient evidence to label them as such.

${ }^{34}$ For example, in Mitsui/CVRD/Caemi, Commission decision of 30th October 2001, case number IV/M.2420, the EC claimed the potential for a maverick but did not explicitly name the party. They simply concluded that the conditions of the market were such that if collusion were to arise then several parties would have an incentive to deviate and behave in a maverick manner. By contrast, in Rexam/American National Can, Commission decision of 19th July 2000, case number IV/M.1939, the EC decided that there could not be a maverick due to the nature of the market.

${ }^{35}$ Linde/BOC, supra note 24, p. 35 .
} 
of the maverick in these 5 cases was around $9 \% .{ }^{36}$ Alternatively, in cases where the maverick was larger (10-20\%), the EC argued that this still underestimated their importance in the market. For example, in StatoilHydro/ConocoPhillips:

"The Commission has considered whether JET Sweden has played a particular role as a low-price competitor putting downward pressure on prices in Sweden. If JET Sweden has acted as a 'pricing maverick' in the Swedish market, the company has played a role in the market which is greater than its market share would imply at first glance." ${ }^{37}$

Generally, in the 5 cases identification of a maverick usually centered on whether they had been increasing their market share in the recent past. This is taken as evidence that they are an aggressive rival and capable of taking custom from the larger firms. For example, in T-Mobile Austria/tele.ring:

"The analysis of market shares alone shows not only that tele.ring has played an active role in the market in the last three years but also that it has been the only company to play such an active role, in terms of increased market share." 38

Moreover, in the Linde/BOC case ${ }^{39}$, another rival was also referred to as an aggressive competitor, but the EC doubted its ability to expand output. In contrast, Linde was seen as having both the ability and incentive to expand. Thus here the emphasis was not only on aggressive pricing but also the potential to expand market share in the future.

\section{B Insider or outsider?}

We can also return to the earlier distinction and identify whether the EC was more likely to establish a maverick when considering an insider or outsider to the merger.

\footnotetext{
${ }^{36}$ Market shares are typically reported as a range in case reports and in this case we take the midpoint. When it is reported as less than $5 \%$ we record this as $5 \%$.

${ }^{37}$ StatoilHydro/ConocoPhillips, supra note 25 , para. 91.

${ }^{38}$ T-Mobile Austria/tele.ring, supra note 20.

${ }^{39}$ Linde/BOC, supra note 24.
} 
Table 3: Mavericks established - insider and outsider distinction

\begin{tabular}{|l|c|c|}
\hline & Total & Maverick established \\
\hline \hline Insider & 13 & 4 \\
\hline Outsider & 9 & 1 \\
\hline
\end{tabular}

Table 3 suggests that the EC was more confident in establishing the existence of a maverick in its more standard setting where the firm is an insider. Moreover, it is in exactly these cases where we expect the concept to contribute to a decision to intervene. In all of the cases where an insider was established as the maverick, remedies were required in that particular market. ${ }^{40}$ These were typically structural divestments. ${ }^{41}$ However, the EC did not go as far as to state that the remedy would restore the pre-merger level of competition by creating a new maverick. Arguably the closest they came to this was in T-Mobile Austria/tele.ring where remedies were geared towards boosting a smaller rival, Hutchison 3G (H3G). The implication was that this was with a view to H3G assuming a maverick-like role of competitive constraint:

"Given the similar incentives and very similar communications profile of $\mathrm{H} 3 \mathrm{G}$ and tele.ring customers, there is strong evidence that $\mathrm{H} 3 \mathrm{G}$ will in future pursue an aggressive price strategy similar to that pursued by tele.ring in the past." ${ }^{2}$

It was hoped that H3G would:

"come to play a bigger role in this market, offering an alternative to the other network operators once 3G-capable mobile telephones become more widespread and once it has built up a nationwide network...."43

T-Mobile/Orange ${ }^{44}$ was the single case in which the EC concluded that there was a maverick that was an outsider to the merger. We would expect the presence of such a firm to go some way toward alleviating authorities' concerns. ${ }^{45}$ It is therefore somewhat surprising that the EC still identified a problem in

\footnotetext{
${ }^{40}$ This is in contrast to the 9 cases where the EC considered the possibility that one of the merging parties was a maverick, but did not establish this. The EC only intervened in 2 of these cases.

${ }^{41}$ In Oracle/Sun Microsystems, supra note 22, these were commitments offered by the parties at the time of notification so officially this case is recorded as a clearance decision.

${ }^{42}$ T-Mobile Austria/tele.ring, supra note 20, p.38.

${ }^{43}$ Id., p.39.

${ }^{44} \mathrm{~T}$-Mobile/Orange, supra note 20.

${ }^{45}$ Furthermore, interventions followed in 7 of the 8 cases where mavericks outside the merger were considered, but not established.
} 
this market and required a divestment remedy. However, the next section will provide an explanation.

\section{THEORIES OF HARM}

Further inspection of the 5 cases in which the EC established the existence of a maverick shows that they all occurred after 2004 when there was a significant change in the ECMR. Prior to this the EC adopted a dominance test for merger analysis. This allowed the EC to intervene in mergers which created or strengthened a singly or collectively dominant position. The latter was regarded as synonymous with tacit collusion/coordinated effects. However, it was argued that the focus on single dominance meant that there was a gap in the legislation. ${ }^{46}$ This was because economic theory ${ }^{47}$ suggests that the potential for price rises without coordinated behaviour is not confined to situations where the merged entity is a singly dominant market leader. Instead, post-merger the merging parties set prices jointly and, because some of the lost demand will be captured by their merger partner, have an incentive to increase prices. The size of this unilateral effect crucially depends on the degree of substitutability between the insiders and outsiders, regardless of whether the merged entity is the market leader. The 2004 change resulted in the dominance test being replaced by a significant impediment to effective competition test. ${ }^{48}$

The initial overall evidence ${ }^{49}$ suggests that this change has resulted in limited application of coordinated effects and an increased reliance on unilateral effects analysis, including some cases that are below the single dominance standard required prior to 2004. Therefore, for each of the cases where the existence of a maverick was established we will next identify the theory of harm in relation to which the role of the maverick was considered.

\footnotetext{
${ }^{46}$ See for example Vickers, J., 2002, How to Reform the EC Merger Test? A speech at the EC/IBA merger control conference, Brussels.

${ }^{47}$ See for example Motta, M., 2004, Competition Policy: Theory and Practice, Cambridge University Press, section 5.2.

${ }^{48}$ See for example Röller, L. H. and De La Mano, M., 2006, The Impact of the New Substantive Test in European Merger Control, European Competition Journal, 2(1): 9-28.

${ }^{49}$ Dethmers, F., 2005, Collective Dominance under EC Merger Control - After Airtours and the Introduction of Unilateral Effects is There Still a Future for Collective Dominance? European Competition Law Review, 26 (11): 638-649 and Davies, S., Olczak, M., and Coles, H., 2011, Tacit Collusion, Firm Asymmetries and Numbers: Evidence from EC Merger Cases, International Journal of Industrial Organization, 29(2): 221-31.
} 


\section{A Theories of harm in cases where the existence of a mav- erick was established}

As outlined in the introduction, both the theoretical foundations and merger guidelines relate the maverick concept to coordinated effects. In the Linde/BOC merger it was clear that the EC applied it in this way. "The removal of Linde... increases the risk of tacit collusion." ${ }^{50}$ However, the examination of the theories of harm used in the other 4 cases provides a much less clear picture.

In StatoilHydro/ConocoPhillips ${ }^{51}$ the EC applied the concept to unilateral effects analysis and this was the only theory of harm considered. Likewise, in Oracle/Sun Microsystems ${ }^{52}$ it appears that the EC also used the concept in a unilateral effects context, whilst still referring to merger guidelines to justify their arguments. As a result, Oracle were highly critical of the theory of harm adopted, arguing that the EC had neither established that the merger resulted in a dominant position nor that the merging parties were close competitors. Furthermore, Oracle argued that the EC had not adequately established that one of the merging parties was a maverick. Interestingly, the EC countered this by making clear that the 2004 change in the ECMR meant that a dominant position was no longer required and by arguing that closeness of competition is only one relevant factor for unilateral effects. In the next sub-section we will examine further how the maverick firm concept fits with unilateral effects analysis under the revised ECMR.

In T-Mobile/tele.ring ${ }^{53}$, the concept was first applied in relation to the EC's main unilateral effects theory of harm. The EC then made clear that it also could not rule out the possibility of coordinated effects and the maverick was again referred to. However, given the commitment offered by the merging parties, they did not need to come to a final decision on this. ${ }^{54}$

Finally, in T-Mobile/Orange the EC moved away from the traditional horizontal theories of harm through unilateral and coordinated effects and instead was concerned about the possibility of foreclosure via future monopolisation of the mobile phone network. Prior to the merger there were agreements between the industry maverick (3UK) and the notifying parties concerning the sharing

\footnotetext{
${ }^{50}$ Linde/BOC, supra note 24, p.35.

${ }^{51}$ StatoilHydro/ConocoPhillips, supra note 25 , para. 91.

${ }^{52}$ Oracle/Sun Microsystems, supra note 22, para. 155-171.

${ }^{53} \mathrm{~T}$-Mobile Austria/tele.ring, supra note 20.

${ }^{54}$ Unilateral and coordinated effects theories of harm were also applied simultaneously in Linde/BOC, supra note 24 . However, in this case the concept was applied solely in relation to coordinated effects.
} 
of mobile network spectrums. The EC's primary concern was that post-merger these agreements would be terminated or quality would be compromised. Thus, the key theory of harm in this instance was the foreclosure of the maverick:

" $3 \mathrm{UK}$ is considered by several market players as an important competitive force in the UK market... The possible disappearance of $3 \mathrm{UK}$ or the degradation of its competitive position could consequently have a serious impact on the UK retail mobile communication market" $" 55$

Therefore, this case provides an example of how the existence of a maverick outsider can increase concerns about the impact of a merger.

\section{B Reconciling the maverick concept with unilateral effects analysis}

The previous sub-section showed that in only 1 of the 5 cases was the application of the maverick concept confined to coordinated effects. More often it was applied either solely or predominantly to unilateral effects, despite the fact that there is no allowance for this in merger guidelines and it is contrary to existing theory. ${ }^{56}$ Indeed, the use of the concept in this setting has also attracted some criticism. For example, commenting on the T-Mobile Austria/tele.ring case, $\mathrm{CRA}^{57}$ describe its use as misleading because:

"Any unilateral effects analysis must model accurately any firm which adopts a business strategy of low cost/low-price. The word 'maverick' adds nothing to the analysis."

Here we discuss whether the use of the concept in unilateral effects analysis may be reconciled with economic theory.

First, consider unilateral effects analysis in which the maverick is an outsider to the merger. It is not immediately apparent why a merger of two nonmavericks would cause a third party maverick to cease to fulfill this role. Therefore, we might expect a maverick outsider to remain so post-merger, at least in

\footnotetext{
${ }^{55}$ T-Mobile/Orange, supra note 20 , p.20.

${ }^{56} \mathrm{It}$ is also interesting to note that in all of the pre-2004 cases in our sample where the concept was considered (but not established), this was only in the context of coordinated effects.

${ }^{57}$ Charles River Associates (CRA), 2006, T-Mobile/tele.ring: analysing mavericks and efficiencies in "the first gap case", competition memo, August 2006, p.1.
} 
the short term. As outlined above, the size of a unilateral effect crucially depends on the degree of substitutability between the insiders and outsiders to a merger. Hence, in line with the CRA argument, unilateral effects analysis should take into account the business models of outsiders, irrespective of whether those outsiders are labelled as maverick or not. The concept therefore adds little to unilateral effects analysis when the maverick in question is an outsider.

What about when the maverick is an insider to the merger? To consider this, first note that the standard theoretical framework underpinning unilateral effects analysis has been criticised for the limited notion of competition it captures. ${ }^{58}$ It is typically assumed, exactly as in the description provided above, that both merging firms continue to operate post-merger and that the only change is that their decisions are now made jointly. This means that there is often little or no consideration of post-merger product repositioning, despite this possibility being recognised in the merger guidelines. ${ }^{59}$ This limitation is clearly seen in the context of simulation techniques which are now commonly used to empirically estimate the unilateral effects of mergers. As Davies and Lyons $^{60}$ discuss, it is difficult to allow for product repositioning in the simulation of the post-merger equilibrium. In contrast, in cases where it is established that one of the merging parties is a maverick, the possibility that the maverick will cease to play its pre-merger role will be a key concern of the EC. Hence, it is possible that by using the maverick concept alongside unilateral effects the EC may be strengthening its argument that post-merger repositioning should be expected.

This possibility certainly fits with the T-Mobile Austria/tele.ring case where unilateral effects were the main concern and where the EC assumed that tele.ring would be removed from the market following the merger ${ }^{61}$ Likewise, in Oracle/Sun Microsystems ${ }^{62}$, the EC argued that the maverick (a subsidiary of Sun Microsystems) could be downgraded post-merger, and the remedies imposed in the case addressed this concern. In contrast, in StatoilHydro/ConocoPhillips ${ }^{63}$

\footnotetext{
${ }^{58}$ See for example comments by D.T Sheffman in Froeb, L. M., Scheffman, D. and Werden, G.J., 2004, Whither Merger Simulation? The Antitrust Source, May, 1-15, p.12.

${ }^{59}$ European Commission, Guidelines on the Assessment of Horizontal Mergers under the Council Regulation on the Control of Concentrations Between Undertakings, supra note 11, para. 30 and Department of Justice and Federal Trade Commission, Horizontal Merger Guidelines, supra note 4, p. 24

${ }^{60}$ Davies, S. and Lyons, B., 2007, Mergers and Merger Remedies in the EU: assessing the Consequences for Competition, Edward Elgar Publishing: Cheltenham, UK, section 4.2.

${ }^{61} \mathrm{~T}$-Mobile Austria/tele.ring, supra note 20, para. 111.

${ }^{62}$ Oracle/Sun Microsystems, supra note 22.

${ }^{63}$ StatoilHydro/ConocoPhillips, supra note 25, para. 195.
} 
the EC simply made clear that the maverick would no longer be an independent competitor. Therefore, this case more closely followed standard unilateral effects analysis and it is hard to see what the maverick concept added.

Overall, when a maverick is an insider, it is possible to reconcile the use of the concept within unilateral effects analysis with the need to consider the possibility that the firm will be repositioned or even closed down post merger. Several of the cases in which the EC established the existence of a maverick amongst the merging parties are consistent with this explanation.

\section{CONCLUSION}

In this paper we have conducted a detailed analysis of the use of the maverick firm concept in EC merger decisions. We found that the concept has been used relatively rarely. However, where it has, maverick behaviour has been considered in a diverse range of industries and the candidate firms have been both insiders and outsiders to the merger. Furthermore, there have only been a few cases in which the EC eventually established the existence of a maverick. In such cases, this is usually a small firm which is an insider to the merger and is perceived to have been an aggressive competitor. All of the cases in which the EC established the existence of a maverick occurred after the 2004 change in the ECMR and predominantly when analysing the possibility of unilateral effects resulting from the merger. We argue that, at least to some extent, this can be reconciled with economic theory by a more general need to take into account post-merger product repositioning.

It is clear from our study that the maverick concept is growing in importance in EC merger decisions. However, there is a need for recognition in guidelines that the concept can apply to firms inside and outside the merger. In addition, further consideration of how the concept fits with unilateral effects analysis and post-merger product repositioning is required, both theoretically and within merger guidelines. 


\section{Appendix}

Table 4: Sectors in which the maverick concept was used

\begin{tabular}{|c|c|c|c|}
\hline Sector & $\begin{array}{l}\text { Total number of } \\
\text { cases }\end{array}$ & $\begin{array}{l}\text { Number of cases } \\
\text { where maverick } \\
\text { concept used }\end{array}$ & $\%$ of total \\
\hline Forestry and Fishing & 4 & 0 & 0 \\
\hline Mining and Quarrying & 6 & 1 & 17 \\
\hline Manufacturing & 178 & 9 & 5 \\
\hline $\begin{array}{l}\text { Electricity, Gas, Steam and Air } \\
\text { Conditioning }\end{array}$ & 19 & 3 & 16 \\
\hline $\begin{array}{c}\text { Water Supply, Sewerage, Waste } \\
\text { Management and Remediation } \\
\text { Activities }\end{array}$ & 2 & 0 & 0 \\
\hline Construction & 3 & 1 & 33 \\
\hline $\begin{array}{l}\text { Wholesale and Retail Trade; Repair } \\
\text { of Motor Vehicles and Motorcycles }\end{array}$ & 12 & 4 & 33 \\
\hline Transportation and Storage & 29 & 1 & 3 \\
\hline $\begin{array}{c}\text { Accommodation and Food Service } \\
\text { Activities }\end{array}$ & 1 & 0 & 0 \\
\hline Information and Communication & 33 & 5 & 15 \\
\hline Financial and Insurance Activities & 11 & 0 & 0 \\
\hline Real Estate Activities & 0 & 0 & 0 \\
\hline $\begin{array}{c}\text { Professional, Scientific and } \\
\text { Technical Activities }\end{array}$ & 4 & 0 & 0 \\
\hline $\begin{array}{c}\text { Administrative and Support } \\
\text { Service Activities }\end{array}$ & 6 & 1 & 17 \\
\hline $\begin{array}{l}\text { Public Administration and Defence; } \\
\text { Compulsory Social Security }\end{array}$ & 0 & 0 & 0 \\
\hline Education & 0 & 0 & 0 \\
\hline $\begin{array}{c}\text { Human Health and Social Work } \\
\text { Activities }\end{array}$ & 1 & 0 & 0 \\
\hline $\begin{array}{l}\text { Arts, Entertainment and } \\
\text { Recreation }\end{array}$ & 5 & 1 & 20 \\
\hline Other Service Activities & 1 & 0 & 0 \\
\hline $\begin{array}{l}\text { Activities of Households as } \\
\text { Employers; Undifferentiated Goods- } \\
\text { and Services - Producing Activities } \\
\text { of Households for Own Use }\end{array}$ & 0 & 0 & 0 \\
\hline $\begin{array}{c}\text { Activities of Extraterritorial } \\
\text { Organisations and Bodies }\end{array}$ & 0 & 0 & 0 \\
\hline Not specified & 5 & 0 & 0 \\
\hline Total & 320 & 26 & 8 \\
\hline
\end{tabular}

